\title{
Thermal properties of products based on ABS I PC
}

\author{
Natalia Romanova ${ }^{1, *}$, Lenar Shafigullin ${ }^{1}$, Azat Gabdrakhmanov ${ }^{1}$, and Svetlana Buyatova ${ }^{1}$ \\ ${ }^{1}$ Kazan Federal University, Sjujumbike street 10a, Naberezhnye Chelny, 420008 Republic Tatarstan
}

\begin{abstract}
Polymer blends are capable of providing materials with extended useful properties beyond the range that can be obtained from single polymers. Acrylonitrile-butadiene-styrene and polycarbonate blends are important industrial materials, especially, in the machine building industry, as ABS improves the processing properties of parts and their toughness, and they also feature positive thermodynamic interaction between PC and styrene-acrylonitrile (SAN) copolymer as a part of ABS. DSC method was used to study the thermal properties of ABS and ABS/PC blends with various ratios. The result from this work shows that abnormal endothermic effect in the ABS glass transition region implies an inadequate manufacturing process for automotive components. The paper studied the influence of $\mathrm{ABS} / \mathrm{PC}$ blend ratios on the value of glass transition temperature and delta $\mathrm{Cp}$, and it was found that the Tg value for SAN/PC increased with decreasing ABS for ABS/PC blends with mass ratio of $75 / 25,60 / 40,50 / 50$.
\end{abstract}

\section{Introduction}

Blending and alloying technology has enhanced the applicability of plastics in automotive applications that had previously been the domain of homopolymers and metals. Polymer blend represents very important field in processing of new materials. The resulting new materials frequently boast synergistically enhanced strength, low temperature impact resistance, high temperature capability, and good paintability. These are all important, if not essential, performance attributes for automotive applications [1].

One of the most highly used alloys in the interior of automobiles is ABS/PC.

Blends of polycarbonate and ABS resins (in bulk or as emulsion) are important industrial materials as ABS improves the processing properties of parts and their toughness. The positive thermodynamic interaction between PC and styrene-acrylonitrile (SAN) copolymer in ABS eliminates the need for compatibilizer in industrial products. However, the morphology of these blends is not stable, and ABS domains get larger at the certain processing stages, resulting in the deterioration of properties [2].

The production of easily molded ABS/PS blends started in the 1960s. The blends consist mostly of polycarbonate, and ABS is added to provide a higher degree of dispersion of the rubber phase. The blends contain 5-40\% of ABS, and they are characterized by high

\footnotetext{
*Corresponding author: misharin_82@mail.ru
} 
impact resistance, which is inherent to ABS, and high modulus of elasticity (stiffness), which is inherent to matrix polymer-polycarbonate [3].

The ABS/PC blends show dimensional stability, low shrinkage and moisture absorption, high stiffness and hardness, good impact resistance at temperatures $\mathrm{T} \geq-50^{\circ} \mathrm{C}$, excellent $\mathrm{UV}$ stability, processability, mechanical properties, heat resistance, flame retardancy, good chemical resistance, but poor to gasoline, aromatic hydrocarbons, esters, ketones and some chlorinated hydrocarbon [1].

ABS/PS components are produced using all the standard manufacturing processes molding, extrusion, thermoforming [3]. ABS/PC blends are used in a variety of automotive components such as instrument panels, flaps for glove compartments, dashboards, and cladding for steering wheel columns, ventilation ports, spoilers, wheel covers and protective side trims. Flame retardant $\mathrm{ABS} / \mathrm{PC}$ blends are used in office equipment and business machine housings. ABS/PC replaces over-engineered straight PC in applications where a higher heat or impact resistance than straight ABS is required [1].

So, the object of this paper is to study the thermal properties of ABS, ABS/PC in order to control the quality of automotive components made by thermoforming of ABS/PC sheets, as well as to show the effect of blend ratios on the thermal properties of ABS/PC compositions. The best method for detecting ABS/PC composition in the different types of automotive components is Differential Scanning Calorimetry (DSC).

\section{Methods}

Differential Scanning Calorimetry was recorded using a Netzsch DSC 204 F1 Phoenix differential scanning calorimeter of the heat flux. DSC analysis was performed in a dynamic heating /cooling mode at a rate of $10{ }^{\circ} \mathrm{C} / \mathrm{min}$ in a stream of argon at a rate of 50 $\mathrm{cm}^{3} / \mathrm{min}$.

\section{Result and discussion}

The ABS/PC blends are having three distinct phases PC, SAN, and an elastomer. The blends are compatibilized by the dipole-dipole interactions between PC and SAN, particularly evident in SAN with $\geq 25 \mathrm{wt} \%$ AN [1].

In most cases, glass transition is measured to evaluate the compatibility of blends; a mutually soluble blend has a single well-defined glass transition temperature ( $\mathrm{Tg}$ ), while a mutually insoluble physical blend has several Tg temperatures, one per each phase. DSC is a useful tool for characterizing the glass transition of amorphous thermoplastics. Detection of one or multiple Tg values with thermal analysis provides important data about the composition of individual amorphous phases in a material [2].

At the first stage, DSC method was used to study the component that had been manufactured by ABS thermoforming. Figure 1 shows DSC scans of the ABS sample for 1st and 2nd heat.

The most pronounced [4,5] thermal effect of $\mathrm{ABS}$ is the glass transition of the polystyrene (PS) component around $100{ }^{\circ} \mathrm{C}$. In low temperature range $\left(<-85^{\circ} \mathrm{C}\right)-$ the polybutadiene transition. Above $100{ }^{\circ} \mathrm{C}$, there is a peak caused by the polyacrylonitrile. Since it is a peak rather than a change in $\mathrm{Cp}$, the peak temperature is recommended for characterization. ABS with a very low content of polyacrylonitrile does not exhibit this peak. Thus, the DSC scans of ABS were analyzed in the temperature range from 25 to 200 ${ }^{\circ} \mathrm{C}$, and only one glass transition was detected in this range. Hence, the glass transition temperature was shifted towards higher temperatures starting from $100^{\circ} \mathrm{C}$, which is typical 
for PS component, and it was equal to $114{ }^{\circ} \mathrm{C}$ with an abrupt change in heat capacity of $0.293 \mathrm{~J} / \mathrm{g} * \mathrm{~K}$.

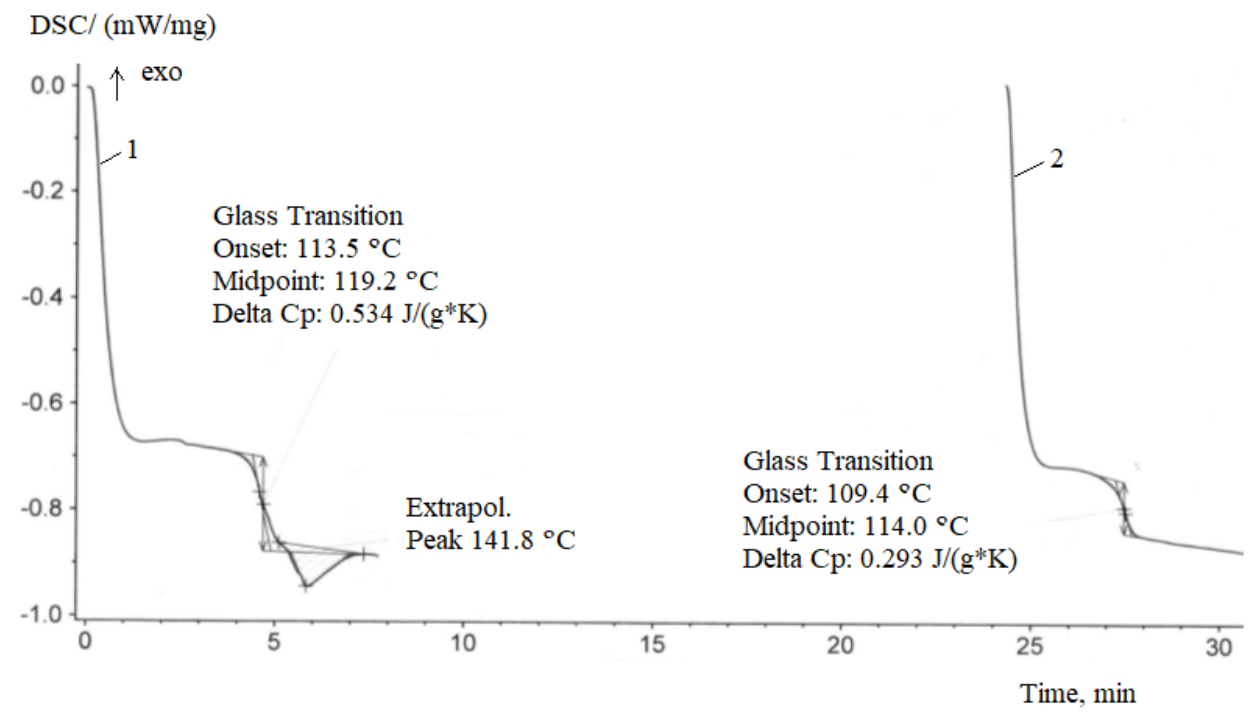

Fig. 1. Glass transition temperature for thermoformed ABS (1- DSC curve of 1st heat, 2- DSC curve of 2nd heat)

It's known, that shifting the glass transition is achieved by incorporating another miscible polymer into the amorphous phase though copolymerization or blending. When two polymers are partially miscible, the $\mathrm{Tg}$ of the mixed amorphous phase will shift between the Tg's of the two homopolymers more or less proportionally to the amount of each component in the mixture. When two polymers are not completely miscible there will be two glass transition, one for each amorphous phase. Acrylonitrile-butadiene-styrene terpolymer is a high performance thermoplastic containing two amorphous phase; a rubbery phase provided by butadiene, and a strength-lending styrene-acrylonitrile copolymer twocomponent phase. So, a single glass transition temperature was observed in the high temperature region of the ABS sample, and it was shifted towards higher temperatures from typical one for polystyrene. That's why, in this paper we specify that high temperature glass transition (in the region of $114^{\circ} \mathrm{C}$ ) is due to the SAN component.

The analysis of DSC scans of the first heat (which is most informative and characterizes the background of samples) showed that in the DSC curve of the studied sample the abnormal endothermic effect was observed in the glass transition region towards higher temperatures (Fig. 1). Hence, the sample had the endothermic peak at $141.8{ }^{\circ} \mathrm{C}$; no endothermic effect was observed during reheat (Fig. 1, curve 2). Therefore, the failure to follow the ABS thermoforming modes [6] results in thermal relaxation and endothermic effect in the region above the glass transition temperature of PS component.

Thus, the presence of abnormal endothermic effect in the glass transition region of the SAN component implies an inadequate manufacturing process for automotive components.

At the next stage, the DSC test was carried out to investigate the effect of ABS/PC blend on the value of glass transition temperature. The results for pure polymers ABS, PC, and $\mathrm{ABS} / \mathrm{PC}$ blends with different compositions are shown in figures 2 .

Figure 2 (curves 1,6 ) shows the DSC results for pure polymers ABS, where the glass transition temperature for SAN-component is found to be $114^{\circ} \mathrm{C}$ and for PC $-152{ }^{\circ} \mathrm{C}$. 
The DSC results for ABS/PC blend samples are shown in Figure 2 (curves 2-5) and table 1; compositions are 75/25, 60/40, 50/50, and 30/70 respectively. For these blend compositions, the Tg's for ABS(SAN-component)/PC are found 113.1/151.3, 114.0/153.3, $115.9 / 155.7$, and $113.5^{\circ} \mathrm{C} / 153.7^{\circ} \mathrm{C}$ respectively. It is observed that the $\mathrm{Tg}$ value for SAN/PC increases with decreasing ABS for ABS/PC blends $-50 / 50$ and then decreases for ABS/PC blends $-30 / 70$.

According to paper [6], for PS/ABS blends, the Tg value decreases with increasing ABS composition and the ABS Tg has been reported as $110^{\circ} \mathrm{C}$.

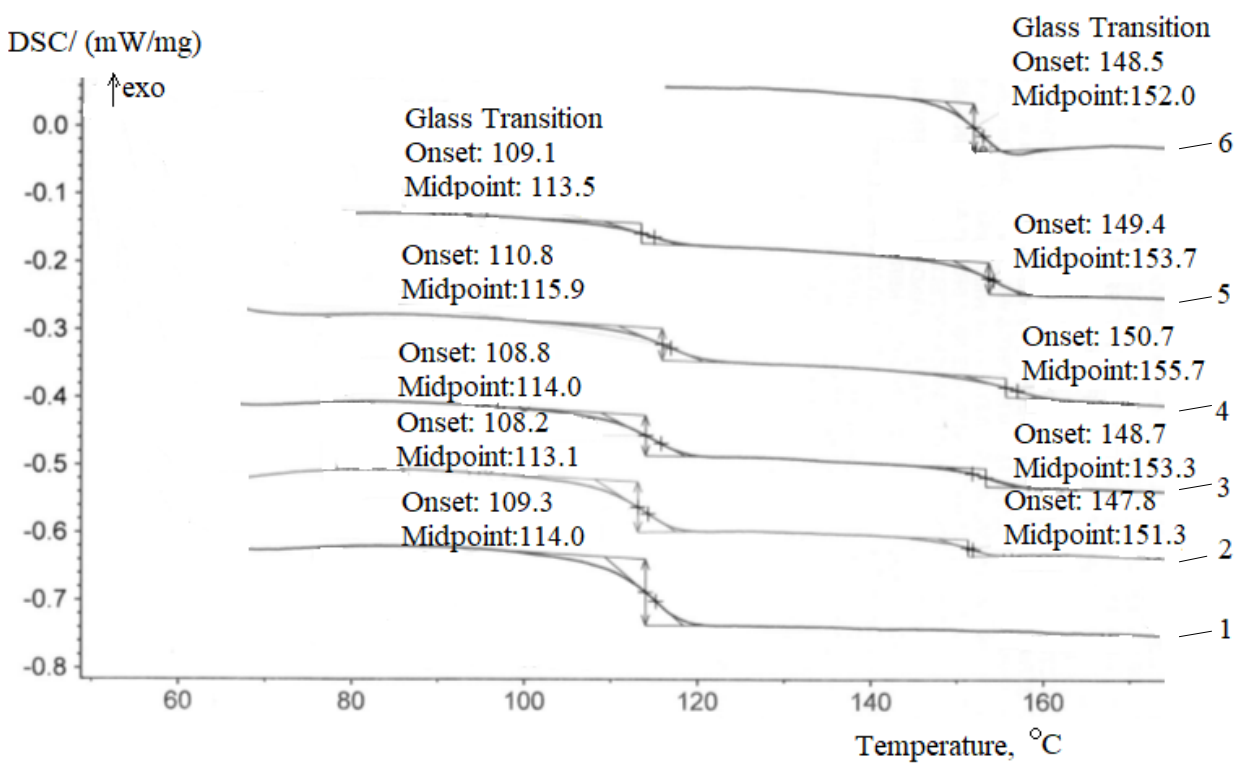

Fig. 2. Glass transition temperatures for pure ABS (1), PC (6), and ABS/PC blends: 75/25 (2), 60/40 (3), 50/50 (4), 30/70 (5)

Table 1. The glass transition temperatures as midpoint and Delta Cp for blends

\begin{tabular}{|c|c|c|c|c|}
\hline $\begin{array}{c}\text { Polymeric blend } \\
\text { ratio for ABS/PC }\end{array}$ & $\begin{array}{c}\text { Tg SAN in } \\
\mathrm{ABS},{ }^{\circ} \mathrm{C}\end{array}$ & $\begin{array}{c}\text { Tg SAN in } \\
\mathrm{ABS},{ }^{\circ} \mathrm{C}\end{array}$ & Tg PC, ${ }^{\circ} \mathrm{C}$ & $\begin{array}{c}\text { Delta Cp PC, } \\
\mathrm{J} / \mathrm{g} * \mathrm{~K}\end{array}$ \\
\hline $100 / 0$ & 114.0 & 0.293 & - & - \\
\hline $75 / 25$ & 113.1 & 0.225 & 151.3 & 0.073 \\
\hline $60 / 40$ & 114.0 & 0.180 & 153.3 & 0.081 \\
\hline $50 / 50$ & 115.9 & 0.141 & 155.7 & 0.084 \\
\hline $30 / 70$ & 113.5 & 0.089 & 153.7 & 0.139 \\
\hline $0 / 100$ & - & - & 152.0 & 0.216 \\
\hline
\end{tabular}

Thermal analysis showed changes in both the SAN in ABS and PC glass transition temperatures (Tg) over the composition range. The major effect was in the ABS/PC blend $=$ $50 / 50$.

A lower Delta Cp value due to a lower blend component is typical for both ABS and PS, which may be indicative of the composition of ABS/PC blend components as it is known for individual polymers [8] that the value of an abrupt change in heat capacity depends on the polymer composition, and the heat capacity increment appears virtually constant for the smallest unit able to move autonomously. Hence, the studied samples have SAN delta Cp (Table 1) of $0.293 \mathrm{~J} / \mathrm{g} * \mathrm{~K}$ and PC delta Cp of $0.216 \mathrm{~J} / \mathrm{g}^{*} \mathrm{~K}$. Most prominent 
decrease in SAN delta Cp is observed after addition of PC to ABS/PC blends (72/25, 60/40, 50/50) - from 0.225 to $0.141 \mathrm{~J} / \mathrm{g} * \mathrm{~K}$, while PC delta Cp almost does not change and varies from 0.073 to $0.084 \mathrm{~J} / \mathrm{g} * \mathrm{~K}$ (Table 1). For these blends, the polycarbonate Tg also increases with increasing polycarbonate content, starting at a depressed value in discrete SAN domain environments and approaching the bulk SAN value.

Hence, for ABS/PC blends (72/25, 60/40, 50/50), with increasing PC, SAN Tg values increase from $113.1^{\circ} \mathrm{C}$ to $115.9^{\circ} \mathrm{C}$, and PC Tg values - from $151.3^{\circ} \mathrm{C}$ to $155.7^{\circ} \mathrm{C}$.

\section{Conclusions}

DSC method was used to study the thermal properties of ABS and ABS/PC blends with ratios of 75/25, 60/40, 50/50, and 30/70 respectively.

The paper studied the influence of ABS/PC blend ratios on the value of glass transition temperature and delta $\mathrm{Cp}$, and it was found that the Tg value for SAN/PC increased with decreasing $\mathrm{ABS}$ for ABS/PC blends with mass ratio of 75/25, 60/40, 50/50, and, with a further PC increase in ABS/PC blend (30/70), Tg values decreased for both ABS and PS.

The thermal studies of ABS/PC compositions can serve as a basis for the quality evaluation method for materials of automotive components according to the composite composition.

\section{References}

1. L.A. Utracki, Polymer Blends Handbook (Published by Kluwer Academic Publishers, P.O. Box 17, 3300 AA Dordrecht, The Netherlands, 2002)

2. D.R. Pau, C.B. Bucknell, Polimernye smesi. Tom I: Sistematika [Polymer blends: Formulation. Volume I.], Translated from English, in Kuleznev, V. N. (ed) (Nauchnye osnovy i tekhnologii, St.-Petersburg, Russia, 2009)

3. V.N. Kuleznev, Smesi i splavy polimerov (konspekt lektsiy) [Polymer blends and alloys: compendium of lectures] (Nauchnye osnovy i tekhnologii, St.-Petersburg, Russia , 2013)

4. ABS glass transition by DSC/ Thermal Analysis Application No.HB 251, p.1-3

5. G.S. Ananthapadmanabha, V.V. Deshpande, Thermal Properties of Acrylonitrile Butadiene Styrene Composites, Indian Journal of Advances in Chemical Science, v. S1, p.279-282 (2016)

6. N.V. Romanova, L.N. Shafigullin, T.M. Kokina, G.R. Shafigullina, Research of the properties of thermoformed products from ABS-plastic sheets, Journal of fundamental and applied science, v. 9, p. 1581-1588, (2017)

7. B.A. Ibrahim, K.M. Kadum, Influence of Polymer Blending on Mechanical and Thermal Properties , Modern Applied Science, v. 4 (9), p. 157-161, (2010)

8. Yu.K. Godovsky, Teplofizicheskie metody issledovaniya polimerov [Thermophysical study methods of polymers] (Khimiya Publ., Moscow, Russia, 1976) 